\title{
Interpersonal behaviour styles of primary education teachers during science lessons
}

\author{
Darrell Fisher $\cdot$ Perry den Brok $\cdot$ Bruce Waldrip $\cdot$ Jeffrey Dorman
}

Received: 18 March 2009/Accepted: 28 August 2009/Published online: 16 December 2011

(C) The Author(s) 2011. This article is published with open access at Springerlink.com

\begin{abstract}
This study reports the first development in Australia of primary science teacher typologies of teacher-student interpersonal behaviour, which was measured by students' perceptions using the Questionnaire on Teacher Interaction (QTI). Earlier work with the QTI in The Netherlands has revealed eight different interpersonal styles, which were later confirmed with an American sample of secondary-school teachers and which were similar to types found with Australian secondary-school science teachers. The present study investigated the extent to which typologies found in earlier studies also apply to primary teachers. A cluster analysis was used to determine Australian typologies and to compare these with earlier findings. Prior typologies could only be partially confirmed, and the found typology of six styles was able to explain variance in both student outcomes and perceptions of cultural elements of the learning environment.
\end{abstract}

Keywords Primary education - Student perceptions of teacher behaviour . Teacher-student interpersonal behaviour - Teaching profile - Typology

D. Fisher

Science and Mathematics Education Centre, Curtin University,

Kent Street, Bentley, WA 6102, Australia

e-mail: d.fisher@curtin.edu.au

P. den Brok $(\square)$

Eindhoven School of Education, Eindhoven University of Technology,

P. O. Box 513, Traverse 3.46, 5600 MB Eindhoven, The Netherlands

e-mail: p.j.d.brok@tue.nl

B. Waldrip · J. Dorman

Faculty of Education, Monash University (Gippsland Campus), Northways Road,

Churchill, VIC 3842, Australia

e-mail: Bruce.Waldrip@monash.edu

J. Dorman

e-mail: Jeffrey.Dorman@monash.edu 


\section{Introduction}

Recent reviews (e.g. Fraser 1998, 2002, 2007; Fraser and Walberg 2005) have demonstrated the importance of the field of classroom environment research, particularly the use of student perceptions, and how this field has contributed much to the understanding and improvement of student outcomes. One common finding in this field is the enormous variety in students' (and teachers') perceptions of the learning environment generally and of perceptions of teacher behaviour specifically as part of this environment (Fraser 2007). This variety can partly be explained by student-related factors that affect perceptions (such as gender, ethnic background, age), class and school factors (such as school type, denomination, location, class size, grade level, subject matter) and also teacher factors (gender, ethnic background, age, experience) (den Brok et al. 2006; Fisher et al. 2006; Fraser 2007; Levy et al. 2003; Wubbels et al. 2006). Research has also shown that differences between classes in terms of the learning environment that remain after taking into account all of the aforementioned factors are systematic and can be captured in terms of classroom profiles or typologies (den Brok et al. 2006; Rickards et al. 2005; Telli et al. 2007b; Wubbels and Brekelmans 1998; Wubbels et al. 2006; Wubbels and Levy 1993). Many of these profiles were established within one particular strand of learning environments research, namely, research on the teacher-student interpersonal relationship, and used one particular instrument to map this behaviour, the Questionnaire on Teacher Interaction (QTI; Wubbels et al. 1985).

Profiles are of importance to both researchers and teacher (educators), as explained by Rickards et al. (2005, p. 268):

Teacher reflection on their own and their students' perceptions of teaching may be further enhanced if information containing these perceptions is presented in various ways (Wubbels 1992). Images or profiles are one of these alternative ways of presenting such information, next to written information on item, scale or (higher order) dimension scores. Images and profiles are powerful tools for reflection because they can be used to conceptualise complex and interrelated information (as is the case with the teacherstudent relationship), because they can summarise information into (smaller) chunks that are easier to comprehend, and because they can stimulate associations and links within the teachers' own knowledge if they are accompanied with powerful labels (e.g. Copeland et al. 1993; Weber and Mitchell 1996; Wubbels 1992).

The present study investigated interpersonal profiles of Australian primary-school teachers while teaching science-using the Australian primary version of the QTI. There were several reasons for undertaking this study. There is some research that suggests different teacher-student interpersonal behaviour exists in primary education compared with secondary education. Speering and Rennie (1996), for example, stated that, in primary education, classroom climate often is more cooperative and caring, whereas classroom climate in secondary education is more academically-oriented, fragmented and competitive. According to these researchers, students perceive their teachers in primary education often as more cooperative and report better contact with their teachers. Their findings seem to be supported by research conducted in primary education with the QTI showing student perceptions of higher teacher influence and proximity compared with secondary education (e.g. den Brok et al. 2005; Ferguson and Fraser 1998). An interesting question is whether these trends are also reflected in the present study. If this is the case, it is not unthinkable that interpersonal profiles will be found that complement known established profiles or that are variants of these known profiles (Wubbels et al. 2006, see also the next section on 
teacher-student interpersonal behaviour and interpersonal profiles). Finally, typologies in previous studies were judged by the amount of variance that they could explain in the scores on the QTI and by differences resulting from classroom observations. However, in most studies, no check was made of whether the new typology could explain significant amounts of variance in student outcomes or other learning environment elements. Such a check would add to current research into associations between student outcomes and the two interpersonal dimensions of influence and proximity, because profiles capture the interaction between the two dimensions in a comprehensive and non-linear manner-rather than treating them as separate, linear entities-and therefore provide a less fragmented picture in explaining outcomes.

Research on teacher-student interpersonal profiles is also important for a number of general reasons:

- Teachers with different interpersonal profiles show different capacity and effectiveness in classroom management (Wubbels et al. 1988, 2006).

- Teachers with different profiles differ in the degree to which they are able to stimulate students in the classroom, the degree to which they differentiate their teaching in terms of teaching methods and the degree to which they provide clear instructions (Brekelmans et al. 2000; den Brok 2001; Wubbels et al. 2006; Wubbels and Levy 1993).

- Teachers with different profiles differ in the degree to which they are able to motivate students in their subject or in the degree to which they stimulate achievement (Wubbels and Brekelmans 1998; Wubbels et al. 2006).

- Teachers with different profiles differ in terms of satisfaction with the profession, the chance to experience burn-out or the chance to leave the profession (Ben-Chaim and Zoller 2001; Wubbels and Levy 1993).

\section{Teacher-student interpersonal behaviour and interpersonal profiles}

The conceptualisation of teacher-student interpersonal behaviour used in the present study has been described by Wubbels and Levy (1993) more completely and is only summarised here. Students' perceptions are studied with the Leary-based (1957) Model for Interpersonal Teacher Behaviour (Wubbels et al. 1985) which describes interpersonal teacher behaviour along two dimensions: Influence (DS, Dominance-Submission) and Proximity (CO, Cooperation-Opposition). The Influence dimension represents the degree of dominance or control displayed by the teacher, while Proximity describes the level of cooperation between teacher and students. The two dimensions can be represented in a coordinate system divided into eight equal sectors (see Fig. 1). The sectors are labelled DC, CD and so on according to their position on the graph. The sectors of the model describe eight different behaviour types: Leadership, Helpful/Friendly, Understanding, Student Freedom, Uncertain, Dissatisfied, Admonishing and Strict.

The Questionnaire on Teacher Interaction (QTI) was developed in The Netherlands in 1984 to gather student and teacher perception data (Wubbels et al. 1985) based on the Model for Interpersonal Teacher Behaviour. Research with the QTI has resulted in a vast and evolving knowledge base on teacher-student interpersonal behaviour (Fraser 1998; Levy et al. 2003; Wubbels and Brekelmans 1998; Wubbels et al. 2006). The QTI has been reliably and extensively used in a host of countries, such as The Netherlands, Australia, the USA, Israel, Korea, Singapore, Brunei, Indonesia and India, among many others (Wubbels et al. 2006). 


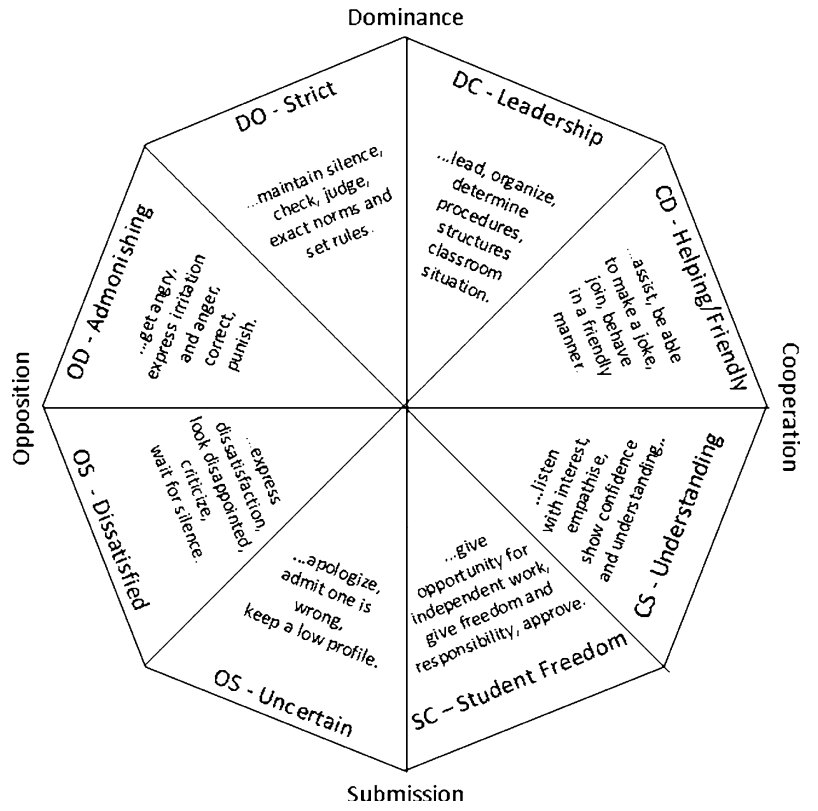

Fig. 1 The model for interpersonal teacher behaviour

Using data gathered with the QTI, researchers in The Netherlands conducted cluster analyses to derive a typology of interpersonal teaching styles of secondary education teachers (e.g. Brekelmans et al. 1993a; Wubbels et al. 1987). The typology found was further validated by observations in classrooms that revealed qualitative differences between each of the eight resulting types. For example, observations of TolerantAuthoritative teachers in secondary education showed the following picture (Brekelmans et al. 1993a, p. 50; for descriptions of observations of the other profiles, see Wubbels et al. 2006):

Tolerant and Authoritative teachers maintain a structure which supports student responsibility and freedom. They use a variety of methods, to which students respond well. They frequently organize their lessons around small group work. While the class environment resembles that of the Authoritative teacher, the TolerantAuthoritative teacher develops closer relationships with students. They enjoy the class and are highly involved in most lessons. Both students and teacher can occasionally be seen laughing, and there is very little need to enforce the rules. The teacher ignores minor disruptions, choosing instead to concentrate on the lesson. Students work to reach their own and the teacher's instructional goals with little or no complaints.

A graphical display of the eight types is presented in Fig. 2. The interpersonal profiles have been labelled as Directive, Authoritative, Tolerant-Authoritative, Tolerant, Uncertain-Tolerant, Uncertain-Aggressive, Repressive and Drudging.

The eight types can be characterised by means of the two dimensions in the Model for Interpersonal Teacher Behaviour (see Fig. 3). The Authoritative, Tolerant-Authoritative and Tolerant profiles are patterns in which students perceive their teachers relatively high on the Proximity Dimension, with the Tolerant type lowest on the Influence Dimension. 
Directive

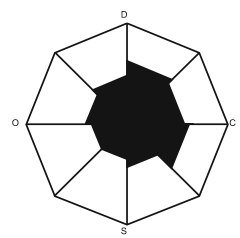

Uncertain-

Tolerant

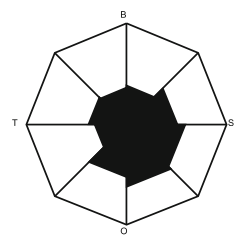

Authoritative

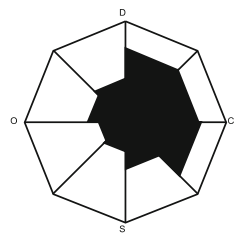

Uncertain-

Aggressive

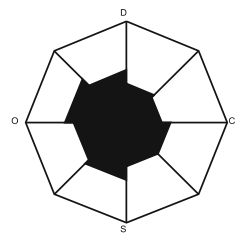

Tolerant-

Authoritative

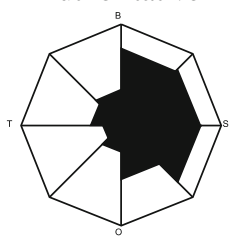

Repressive

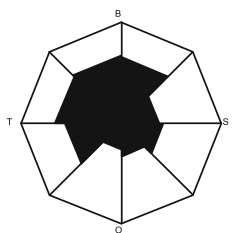

Tolerant

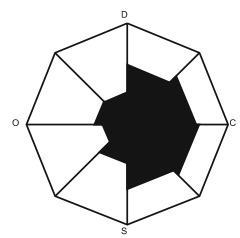

Drudging

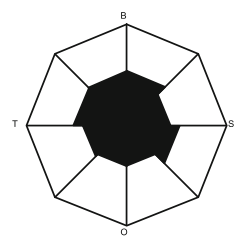

Fig. 2 Graphic representations of the eight types of patterns of interpersonal relationships

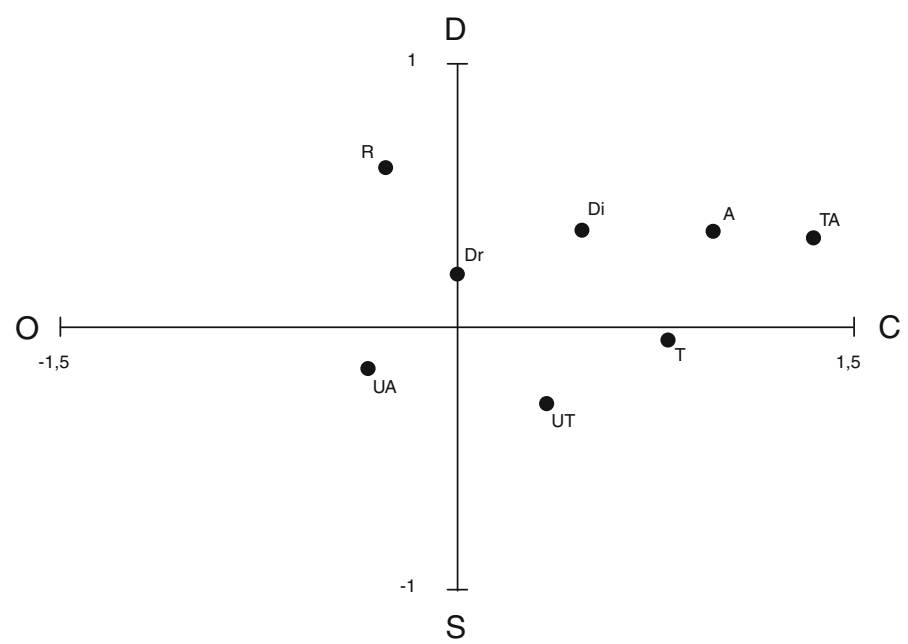

Fig. 3 The eight interpersonal profiles positioned on the two interpersonal dimensions

Less cooperative than the three previous types are the Directive, Uncertain-Tolerant, and Drudging profiles, with the Uncertain-Tolerant type lowest on the Dominance Dimension. The least cooperative pattern of interpersonal relationships is demonstrated by the Repressive and Uncertain-Aggressive types. Repressive teachers are the most dominant of all eight types.

The eight interpersonal types have also been linked to student outcomes (Brekelmans et al. 1993a). Repressive teachers, followed by Tolerant and Directive teachers, realised highest cognitive achievement. The lowest cognitive achievement was found in classes of Uncertain-Tolerant and Uncertain-Aggressive teachers. The highest motivation has been found in classes of Authoritative, Tolerant-Authoritative and Directive teachers, while the 
lowest motivation occurred in classes of Drudging and Uncertain-Aggressive teachers. The pattern found for the Tolerant-Authoritative teachers approximates the image of the 'best' or 'ideal' teacher (Wubbels and Levy 1993).

Because students' (and teachers') perceptions on the QTI comprise observations over a longer period of time, interpersonal styles (and therefore the typology) are rather stable. Nevertheless, different profiles can be found in different classes of teachers (e.g. Wubbels and Levy 1993) and teachers seem to change from type to type over their teaching careers (e.g. Brekelmans et al. 2005). Major types during the student teaching period are the Tolerant and Tolerant-Uncertain profiles. Authoritative and TolerantAuthoritative profiles can be found more often after 2 years of experience in teaching. Towards the end of the teaching career the number of teachers with Repressive profiles increases. No differences in profiles have been reported between male and female teachers.

The eight typical profiles originally found in Dutch samples were confirmed in a USA sample (Wubbels and Levy 1993), and appeared to be similarly distributed over the population of teachers. When Telli et al. (2007a) conducted cluster analyses on student perception data of Turkish secondary science teachers with a sample of 7,484 students in 278 classes, they found different interpersonal profiles. The most common-in terms of the original typology-were the Authoritative and Tolerant-Authoritative teachers (with 88 classes, $31.7 \%$ each and $63.4 \%$ in total). These were followed by Directive teachers (69 classes, $24.8 \%$ ). Other types were found in considerably smaller numbers compared with the first three. The results of the cluster analyses showed that the best and most distinctive typology found in the data consisted of six types that were labelled TolerantDirective, Tolerant-Authorative (with a higher score for strict than the original), Uncertain-Tolerant (with a higher amount of leadership and lower amount of student freedom than the original), Directive, Authoritative and Repressive. However, many teachers in this typology could be classified in terms of the original USA/Dutch typology. Because the Turkish typology explained similar or lower amounts of variance in QTI scales and dimensions, and because profiles to a large degree corresponded with the original typology, it seemed that the original typology also applied to the Turkish context.

Rickards et al. (2005) investigated interpersonal styles with Australian secondary education science teachers with a sample of 6,148 students. Their study showed a number of interesting results. In the Australian sample, several profiles were less common, such as the Tolerant, Uncertain-Aggressive and Uncertain-Tolerant types, whereas other profiles were much more common, such as the Authoritative and Tolerant-Authoritative types. According to the authors, these findings reflected a lower presence of uncertainty in Australian teachers' behaviour and a higher degree of respect and formality compared with Dutch or American classrooms. The results of their analyses provided support for the existence of a relatively replicable typology of seven distinct interpersonal patterns. Four out of the seven types in the Australian sample resembled earlier constructed types to such a degree that they were considered similar: Tolerant-Authoritative, Authoritative, Directive and Uncertain-Aggressive. However, three new profiles were found. One of these seemed to be a clear-cut combination of two existing types and was labelled as DirectiveAuthoritative. The two remaining types seemed unique to the Australian context and were labelled as Flexible and Cooperative-Supportive. These last two types were characterised by large amounts of helping/friendly and understanding behaviours, and moderately high amounts of both leadership and student freedom behaviours. The three new Australian profiles (secondary education) are displayed in Fig. 4. 


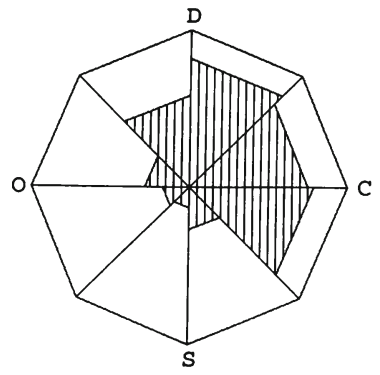

Directive-Authoritative

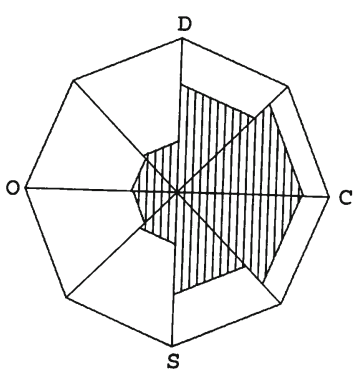

Flexible

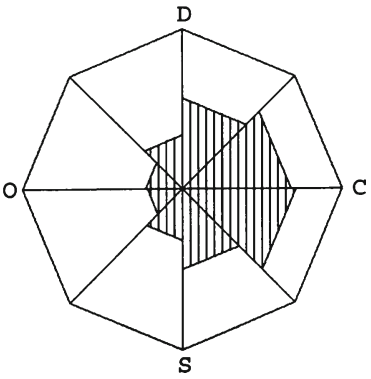

Cooperative-Supportive

Fig. 4 Three original Australian interpersonal types (secondary science)

\section{Research objectives}

The objectives of this study were to investigate:

- the distribution of interpersonal profiles (as used in prior research) for a large sample of Australian primary-school teachers

- whether a specific Australian typology of interpersonal teacher behaviour for primary education exists and to what degree it resembles typologies found in earlier research

- associations between the primary education typology, students' enjoyment of their science lessons and their perceptions of other learning environment elements (here the cultural climate in their classroom).

The last research question was added because research investigating associations between interpersonal profiles and outcomes or other teacher behaviours is relatively scarce (see Introduction section for some exceptions) and usually concerns teaching methods or teacher regulation strategies. Because the data set analysed for the present study originated from a larger national teacher professional development project, it conveniently contained data on student perceptions of cultural dimensions of their classroom; this opportunity was taken to add a new perspective to the current knowledge base on interpersonal profiles.

\section{Method}

Sample

The study involved 2,178 students in 103 years 5, 6 and 7 primary classrooms in three Australian states. The survey was administered to the sample to collect information on students' perceptions of their teachers' interpersonal behaviour when teaching science, perceptions of the cultural climate of the classroom and students' enjoyment of their science lessons.

From the sample, only students (and classes) with complete data on all instruments were used in analyses. Because data on students' perceptions of teacher-student interpersonal behaviour were not available for 23 classes, data from the remaining 80 classes $(1,697$ students) were used for achieving the research objectives. A $t$ test comparing ratings of student enjoyment and cultural dimensions of the classroom between the selected and 
non-selected classes showed that the non-selected classes had statistically significant lower ratings of enjoyment $(t=-6.45, p<0.01)$ but higher ratings of equity $(t=2.06$, $p<0.025)$ and congruence $(t=2.60, p<0.01)$ in the classroom. The selected classes did not differ in terms of student gender or grade level; however, they did come from a small number of schools (equally spread across the different states).

Of the students included in the analyses, $51.4 \%$ were female. Also, $32.7 \%$ were Grade 5 students, $32.1 \%$ were in Grade 6 and the remainder of the students $(35.3 \%)$ were in Grade 7. No information is available on how representative this sample is of the Australian primary education population of students.

\section{Instrumentation}

\section{Teacher-student interpersonal behaviour}

Data about the perceptions of students of their teachers' interpersonal behaviour were gathered by means of the QTI, which has demonstrated high validity and reliability in various countries (e.g. den Brok 2001; Wubbels and Levy 1993). The Australian primary education version of the QTI was distributed among the students. This version consists of 48 items which are answered on a five-point frequency scale. These items are divided into eight scales which conform to the eight sectors of the model. The Australian version of the QTI has shown adequate reliability and validity, both for primary and secondary education students (e.g. den Brok 2001; Fraser 2002; Wubbels and Levy 1993).

For the present sample, reliability (Cronbach's alpha) of the QTI scales ranged from 0.60 to 0.81 for the student level and from 0.80 to 0.92 for the class level (see Table 1). We analysed the perceptions of the teacher-student relationship on the basis of dimension scores (linear combinations of the eight scale scores): an Influence score and a Proximity score (see Wubbels and Brekelmans 2005). The higher these scores are, the more influence or proximity was perceived in the behaviour of a teacher. The intra-class correlation ranged between 0.15 and 0.28 for QTI scales, was 0.18 for Influence and was 0.32 for Proximity. These results suggest that the instrument is capable of distinguishing between Australian primary education classes.

The construct validity of the Australian primary education QTI was investigated in a number of ways. First, an exploratory factor analysis (maximum likelihood, rotation by hand; e.g. den Brok 2001) was conducted on the (aggregated) scale scores in order to see whether two dimensions (or factors) were present in the data. This analysis indicated that

Table 1 Cronbach's alpha coefficient at the student and class levels and intraclass correlations for QTI scales

Each scale contains 6 items

\begin{tabular}{llll}
\hline Scale & $\alpha$ reliability & & $\begin{array}{l}\text { Intra-class } \\
\text { correlation }\end{array}$ \\
\cline { 2 - 3 } & Student & Class & \\
\hline DC-Leadership & 0.68 & 0.80 & 0.15 \\
CD-Helpful/friendly & 0.81 & 0.90 & 0.22 \\
CS-Understanding & 0.80 & 0.92 & 0.20 \\
SC-Student freedom & 0.72 & 0.83 & 0.20 \\
SO-Uncertain & 0.61 & 0.81 & 0.15 \\
OS-Dissatisfied & 0.69 & 0.88 & 0.22 \\
OD-Admonishing & 0.74 & 0.90 & 0.28 \\
DO-Strict & 0.60 & 0.82 & 0.22 \\
\hline
\end{tabular}


two factors with eigenvalues larger than 1.0 could be extracted. These two factors explained $78.5 \%$ of the variance. Factor loadings could be interpreted in terms of a Proximity dimension (first factor) and an Influence dimension (second factor). The scales of Helping/Friendly and Understanding were closely located on the interpersonal circle indicating an overlap, and a similar finding occurred for Dissatisfied and Admonishing.

Secondly, to further explore whether the MITB (Model for Interpersonal Teacher Behaviour) applied to the data, multilevel confirmatory factor analyses (with Mplus) were conducted. Two models were tested, an ideal interpersonal circumplex model (e.g. Fabrigar et al. 1997; Gaines et al. 1997), exactly representing Fig. 1, and an irregular circumplex model (a model with two, independent dimensions and free factor loadings e.g. Fabrigar et al. 1997; Gaines et al. 1997). These confirmatory factor analyses (Mplus) indicated that the ideal circumplex model displayed moderate fit $\left(\chi^{2}=189.87\right.$ with $d f(26)$ and $p$-value of 0.00; CFI $=0.97$; TLI $=0.93$; RMSEA $=0.06$ and SRMR (between) $=$ $0.17)$. The irregular circumplex model with two uncorrelated dimensions and scales ordered in a circle with free positions on circumplex showed satisfying fit $\left(\chi^{2}=81.23\right.$ with $d f(15)$ and $p=0.00 ;$ CFI $=0.99$; TLI $=0.95$; RMSEA $=0.05$; SRMR (between) $=$ $0.09)$.

Thirdly, the correlation between the two dimensions of Influence and Proximity was statistically nonsignificant (0.04) and in line with model assumptions (e.g. Fabrigar et al. 1997).

\section{Students' science-related attitudes}

To assess students' attitude to their class, a seven-item scale based on the Test of ScienceRelated Attitudes (TOSRA; Fraser 1981) was devised (Fisher et al. 1997). The TOSRA scale Enjoyment of Science Lessons (Fraser 1981) was chosen for this study. It has been shown that enjoyment (or pleasure) is strongly related to other attitudinal concepts and elements, such as relevance, confidence, interest and effort (e.g. den Brok 2001). Thus, the more enjoyment that students experience in science, the more relevance that they attach to science for their future education and occupation, the more confidence that they have in performing well in science, the more interested that they are in science, and the more effort that they are willing to invest into learning science. For the Enjoyment scale, a Cronbach alpha of 0.88 was found at the student level and of 0.95 at the class level. On a scale of $0-1$, the average score was 0.68 and the standard deviation was 0.20 . The ICC was 0.20 , indicating that about $20 \%$ of the variance was at the class (and school) levels.

\section{Cultural learning environment}

Fisher and Waldrip (1999, 2002) developed the Cultural Learning Environment Questionnaire (CLEQ) specifically to assess cultural factors of the classroom learning environment. This questionnaire contains 35 items in seven scales: Equity, Collaboration, Deference, Competition, Teacher Authority, Modelling and Congruence. Each scale contains five items that are responded to on a five-point scale. Students are asked to indicate to what extent they agree that each item describes their classroom. The CLEQ has been shown to be a valid and reliable instrument (Dhindsa 2005; Dhindsa and Fraser 2004; Fisher and Waldrip 1999). It was decided to modify the CLEQ for use in primary schools in this study. Part of this modification involved a reduction in the number of scales to three, namely, Equity, Collaboration and Congruence, to alleviate workload for the students. These scales were selected because they were consistent predictors of students' attitudes 
Table 2 Cronbach's alpha coefficient, average scale correlation and variance at class level for CLEQ scales

\begin{tabular}{|c|c|c|c|c|c|}
\hline \multirow[t]{2}{*}{ Scale } & \multicolumn{2}{|c|}{$\alpha$ Reliability } & \multicolumn{2}{|c|}{ Average scale correlation } & \multirow{2}{*}{$\begin{array}{l}\text { Variance at } \\
\text { class level }\end{array}$} \\
\hline & Student & Class & Student & Class & \\
\hline Equity & 0.72 & 0.85 & 0.49 & 0.63 & 10.0 \\
\hline Collaboration & 0.73 & 0.81 & 0.49 & 0.63 & 4.8 \\
\hline Congruence & 0.80 & 0.89 & 0.49 & 0.63 & 8.5 \\
\hline
\end{tabular}

and cognitive achievement in previous research using the questionnaire (Fisher and Waldrip 2002). Therefore, the CLEQ (primary) contained 15 items which had been construct and content validated by teachers, students and fellow researchers. Given the fact that the CLEQ was originally devised for secondary education students, it was decided to elaborately establish validity and reliability for the present study conducted in primary education. First, a factor analysis was conducted on the 15 CLEQ items at the class level. This analysis indicated that three factors with an eigenvalue larger than 1.0 could be extracted, explaining $68.0 \%$ of the variance. A varimax rotation of the factor loadings indicated that most of the items conformed to their a priori scales (see the Appendix). As a second step, unidimensionality of the three scales was checked by computing Cronbach's alpha, both at the student and class level. As can be seen in Table 2, all three scales were perceived as reliable $(\alpha>0.70)$, with the Congruence scale having the highest alpha coefficient. The mean correlation of each of the scales with the other two scales was used as a measure of discriminant validity. Associations between the scales are moderate to strong, but sufficiently low to suggest that the three elements are distinct from each other. As can be seen in Table 2, roughly 5-10\% of the variance in each CLEQ scale is located at the class level.

\section{Analyses}

In order to answer the research questions, a number of analyses were performed. First, with SPSS, we determined which of the eight existing interpersonal profiles resembled the classes of each participating teacher best. This way, it could be established what kind of distribution of (earlier constructed) interpersonal types was present in the sample. If the distribution differs from those found in the USA and The Netherlands, this might be an indication of weak applicability of the existing interpersonal typology to the Australian context.

Secondly, to create a specific typology for the Australian sample of teachers, we performed a cluster analysis. According to Brekelmans (1989), who was the first researcher to use cluster analyses for establishing interpersonal profiles with the QTI, it is important in the profile construction process to look for differences between types with respect to the magnitude within each of the eight sector scores (elevation), the variance in the sector scores (scatter) and the overall pattern displayed in the sector scores (shape). Squared Euclidian distances and the complete linkage method were used to create clusters and assign teachers.

Thirdly, outcomes of the cluster analysis described above were verified. An analysis of variance (ANOVA) on the eight sector scores and two dimensions with the constructed typology as the explanatory variable was used to check if sufficient amounts of variance could be explained by the cluster outcomes. By doing so, the optimal cluster solution 
(in terms of the number of types) could be established. In order to interpret findings, outcomes of the Australian classification were also represented graphically in terms of the eight sector or scale scores.

Fourth, analyses of variance were conducted on class aggregated scores for Enjoyment of Science Lessons and perceptions of Equity, Collaboration and Congruence with the new and old typology as the explanatory variable. This way, it could be checked whether the old and new typologies explained similar amounts of variance in these variables and which profiles showed highest, and lowest scores. A qualitatively distinct set of profiles should be able to explain similar or higher amounts of variance than the existing set of profiles, in order to be of significant (research) value. Finally, differences in class size, percentage of girls in the classroom and grade level were determined between the profiles in order to see whether any distinctive trends could be found in the data, and therefore help to explain some of the findings for the first three research objectives.

\section{Results}

Distribution of existing profiles

Based on scale scores, teachers were classified in terms of the existing, eightfold typology of interpersonal styles. The percentages of teachers belonging to each type are reported in Table 3 and compared with the results of previous studies.

When compared with previous findings, our results showed that $83.6 \%$ of the teachers belonged to the first three types (Directive, Authoritative or Tolerant-Authoritative). More Drudging, Authoritative and Tolerant-Authoritative teachers and less Uncertain-Aggressive, Uncertain, Tolerant teachers were found in this primary education sample as compared to a Dutch (secondary) sample. However, apart from different proportions of Repressive and Authoritative teachers, a similar distribution was found with the primary education Australian sample as with the secondary Australian teachers.

The Brekelmans et al. (1993a) typology explained between $41.7 \%$ (Uncertain) and $80.3 \%$ (Dissatisfied) of the variance in scale scores. Also, it explained $17.3 \%$ of the variance in Influence and $87.7 \%$ of the variance in Proximity.

Table 3 Percentages of teachers belonging to interpersonal profiles in the present study and in previous (QTI) studies (absolute number of teachers between brackets)

\footnotetext{
a Rickards et al. (2005)

b Brekelmans et al. (1993a)
}

\begin{tabular}{lcccc}
\hline Interpersonal type & $\begin{array}{l}\text { Australian } \\
\text { primary }\end{array}$ & & $\begin{array}{l}\text { Australian } \\
\text { secondary }\end{array}$ & $\begin{array}{l}\text { Dutch sample } \\
\text { secondary }\end{array}$ \\
\cline { 2 - 3 }$\%$ & $n$ & $\%$ & $\%$ \\
\hline Directive & 22.4 & 18 & 15.5 & 18.2 \\
Authoritative & 25.0 & 20 & 37.5 & 14.9 \\
Tolerant-Authoritative & 36.2 & 29 & 33.9 & 10.4 \\
Tolerant & 6.3 & 5 & 6.0 & 23.5 \\
Uncertain-Tolerant & 1.3 & 1 & 1.4 & 15.3 \\
Uncertain-Aggressive & 0.0 & - & 1.1 & 6.5 \\
Repressive & 3.8 & 3 & 0.7 & 3.2 \\
Drudging & 5.0 & 4 & 3.9 & 0.3 \\
Unable to classify & - & - & - & 7.7 \\
Total & 100.0 & 80 & 100.0 & 100.0 \\
\hline
\end{tabular}


Creating a new typology

Using cluster analysis (squared Euclidian distances, complete linkage method), cluster solutions between three and 10 types were tested. With more than six clusters in the solution, the last clusters consisted of one or two classes with less typical profiles. With less than six clusters, the solutions explained little variance in scales or dimensions and some clusters seemed to contain much within-type variation. Based on these findings, a cluster solution with six different types was chosen. The cluster solution explained $17.1 \%$ of the variance in Influence and $90.8 \%$ of the variance in Proximity. Also, it explained between $44.3 \%$ (Uncertain) and $82.4 \%$ (Dissatisfied) of the variance in scale scores. These percentages are slightly higher than for the original typology (between 40.6 and $80.0 \%$ ). Nevertheless, the new typology explained slightly less variance in Influence compared to the old typology (22.8\%), but slightly more variance in Proximity (old typology $87.7 \%$ ). Figure 5 provides a graphical display of the six types found.

Type 1 is a combination of the Directive and Tolerant-Authoritative teacher and seems to be a new profile. It contains similar amounts of Leadership, Helpful/Friendly and Understanding from the original Directive teacher profile, but has higher amounts of Student Freedom (actually the amount to be found with the Tolerant-Authoritative teacher). On the other hand, this profile has more Strictness and Admonishing than can be found in the original Directive profile. This profile is labelled as a Directive-Authoritative teacher.

Type 2 closely resembles the Supportive profile from the Rickards et al. (2005) typology. It comes closest to the original Tolerant teacher (Brekelmans et al. 1993b) but has a much higher amount of student freedom and a somewhat lower amount of uncertainty compared with the Tolerant teacher.

Type 3 is labelled as the Supportive-Demanding teacher because it resembles best the Rickards et al. (2005) Supportive teacher, but contains higher amounts of strictness. Thus, it has all the hallmarks of the Tolerant teacher, with higher amounts of Student Freedom
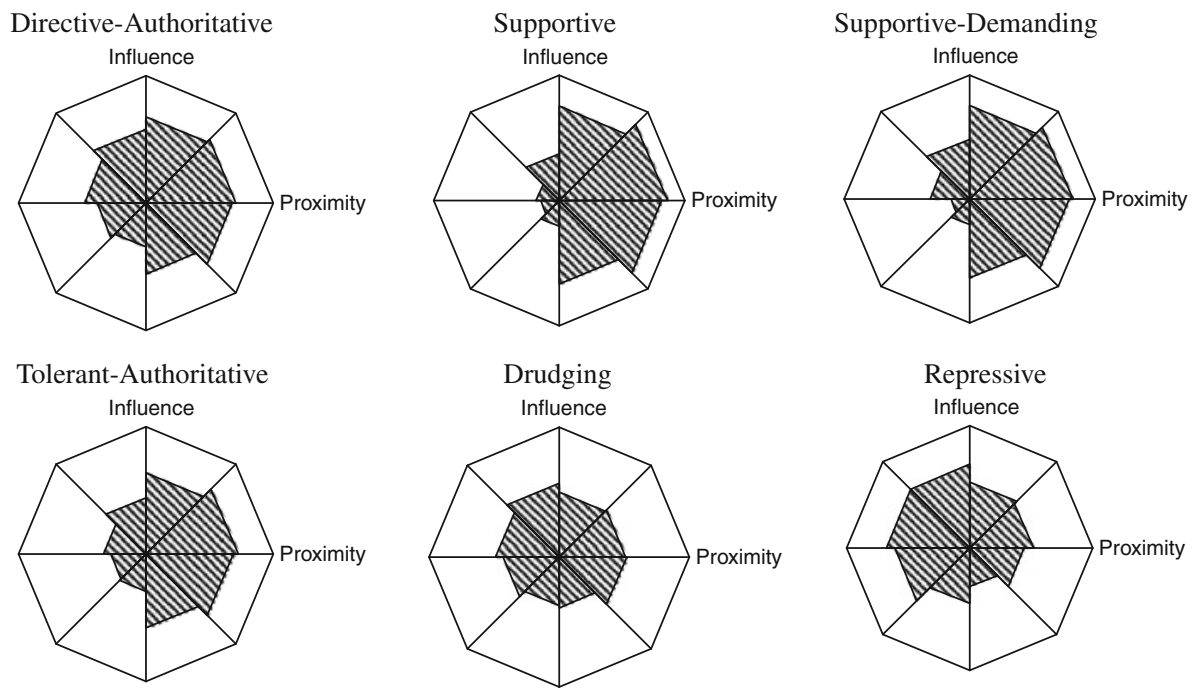

Fig. 5 Graphical profile of the six types of the cluster solution 
and lower amounts of Uncertainty than the Tolerant teacher, but with higher amounts of Strictness than the original Supportive teacher. It seems to combine characteristics of the Tolerant-Authoritative, Tolerant and Directive teachers from the original Brekelmans et al. typology.

Type 4 seems to resemble the Tolerant-Authoritative teacher from the original Brekelmans typology most closely, although it has a slightly higher amount of tolerance (in particular Student Freedom) compared with the original Tolerant-Authoritative teacher. The Tolerant-Authoritative teacher is the most common profile found in the present study.

Types 5 and 6 resemble the Drudging and Repressive teachers from the original Brekelmans typology. The Repressive teacher (type 6) has the lowest amount of Proximity (it is the only type with a negative amount of Proximity) and the highest amount of Influence of all six types found. The Drudging type has the second lowest (but slightly positive) amount of Proximity and a medium amount of Influence compared with the other five types.

In Table 4, the percentages of occurrence of each of the six types are displayed. As can be seen, the Tolerant-Authoritative profile is most common, followed by the DirectiveAuthoritative profile and the Supportive profile. Drudging teachers were least common in the sample.

\section{Interpersonal profiles and other classroom environment variables}

For each of the six new interpersonal profiles, the mean amount of Enjoyment, Equity, Collaboration and Congruence (as well as the variance) was computed. The results of this analysis are presented in Table 5.

The results show that, in the classes of Tolerant-Authoritative teachers, students enjoyed their classes more than did other types. The students in the classrooms of Drudging teachers had the least Enjoyment. The cluster solution of six types explained $22.6 \%$ of the variance in Enjoyment. This percentage is a little higher than the amount of variance explained by the original typology (which was $20.0 \%$ ).

As for Equity, it appears that this was perceived to be highest in Supportive classes, followed by Tolerant-Authoritative classes. Teachers with Drudging profiles were perceived lowest in terms of Equity. The new typology explained $7.8 \%$ of the variance in Equity, which was lower than the amount of variance explained by the old typology (18.1\%). Supportive teachers were perceived highest on Collaboration, while SupportiveDemanding teachers were perceived lowest on Collaboration. The old typology explained $16.5 \%$ of the variance in Collaboration, whereas the new typology explained 25.6\%. As for Congruence, Tolerant-Authoritative teachers and Supportive teachers were perceived highest with respect to this learning environment element, Drudging teachers were

Table 4 Percentage frequency of occurrence of the new cluster profiles

\begin{tabular}{lrr}
\hline Cluster type (new) & $\%$ & $f$ \\
\hline Directive-Authoritative & 20.0 & 16 \\
Supportive & 15.0 & 12 \\
Supportive-Demanding & 12.5 & 10 \\
Tolerant-Authoritative & 30.0 & 24 \\
Drudging & 10.0 & 8 \\
Repressive & 12.5 & 10 \\
Total & 100.0 & 80 \\
\hline
\end{tabular}


Table 5 Mean (and variance) in enjoyment, equity, collaboration and congruence for each of the six interpersonal profiles

\begin{tabular}{|c|c|c|c|c|c|c|c|c|}
\hline \multirow[t]{2}{*}{ Cluster type } & \multicolumn{2}{|c|}{ Enjoyment } & \multicolumn{2}{|c|}{ Equity } & \multicolumn{2}{|c|}{ Collaboration } & \multicolumn{2}{|c|}{ Congruence } \\
\hline & Main & Variance & Main & Variance & Main & Variance & Main & Variance \\
\hline Directive-Authoritative & 0.70 & 0.08 & 0.73 & 0.07 & 0.72 & 0.05 & 0.68 & 0.06 \\
\hline Supportive & 0.71 & 0.08 & 0.80 & 0.06 & 0.78 & 0.06 & 0.73 & 0.07 \\
\hline Supportive-Demanding & 0.71 & 0.07 & 0.76 & 0.06 & 0.69 & 0.08 & 0.70 & 0.06 \\
\hline Tolerant-Authoritative & 0.77 & 0.08 & 0.77 & 0.06 & 0.74 & 0.08 & 0.73 & 0.05 \\
\hline Drudging & 0.59 & 0.11 & 0.73 & 0.09 & 0.71 & 0.08 & 0.62 & 0.09 \\
\hline Repressive & 0.68 & 0.08 & 0.75 & 0.09 & 0.74 & 0.08 & 0.68 & 0.09 \\
\hline Average across types & 0.69 & 0.09 & 0.76 & 0.08 & 0.74 & 0.07 & 0.69 & 0.08 \\
\hline
\end{tabular}

Variables are scored on a range between $0(\min )$ and $1(\max )$

perceived lowest. The new typology explained $17.5 \%$ of the variance in Congruence, whereas the old typology explained $21.7 \%$.

Class size hardly differed between classes of the six profiles. Average class size was highest for Drudging classes (22.0), followed by Supportive classes (21.1), DirectiveTolerant classes (20.9), Repressive classes (20.9), Supportive-Demanding classes (20.0) and finally Tolerant-Authoritative classes (17.2). The percentage of girls also hardly differed between the six profiles. The highest percentage of girls was found in TolerantAuthoritative classes (54.4), followed by Drudging classes (51.6), Directive-Authoritative classes (51.5), Supportive-Demanding classes (48.9), Supportive classes (47.2) and Repressive classes (42.4).

While all six types could be found at all grade levels involved of the study, some profiles seemed (relatively) more common in certain grade levels than others. For example, of the 22 Grade 5 classes in the study, seven belonged to the Supportive-Demanding profile (there were only 10 Supportive-Demanding classes in total). Also, from the 34 Grade 6 classes, 8 belonged to the Directive-Authoritative profile (16 classes of the total sample belonged to this profile). Of the 10 Repressive classes, 5 were located in Grade 6 . Finally, of the 24 Grade 7 classes, 10 were of the Tolerant-Authoritative profile. The Drudging and Supportive profiles were distributed equally among the different grade levels.

\section{Discussion}

Using cluster analysis, we identified a new Australian typology of primary education teachers and compared it with existing Dutch/USA typologies for secondary education. The results of this analysis provided support for the existence of a relatively replicable typology of six distinct interpersonal patterns in primary education. Three of the types resemble previously-found profiles in secondary education (e.g. Tolerant-Authoritative, Drudging and Repressive), while three new profiles were found, one of which resembled the Supportive profile that was found as a new profile in a previous Australian (secondary science) sample. The cluster solution explained slightly higher amounts of variance in QTI scale scores compared with the original Dutch typology and also explained slightly more variance in Enjoyment than did the original typology.

In terms of Influence and Proximity, the old and new typologies explained roughly similar amounts of variance. However, at the same time, the cluster solution seemed less 
effective in explaining differences between classes in Equity, Collaboration and Congruence than did the old typology. It should be noted that some profiles in the old typology could be found in only 1 or 2 classes, which could have resulted in relatively large differences between them with respect to some associating variables, while profile distribution was much more equivalent in the new typology. As a result, one or two classes could have affected the results of the old typology much more strongly than they did in the new typology. Also, even though some percentages of explained variance were lower, they were still considerable (up to 20\%), suggesting that the typology is useful in explaining other learning environment elements and student outcomes as well.

The results of this study again confirmed that earlier classifications only partially apply to the Australian primary education situation. Moreover, the fact that only some of the previous profiles found in secondary education emerged for this sample seemed to suggest that teachers in primary education actually do have different interpersonal styles compared with secondary education teachers and that they realise different types of classroom climates. In particular, we found a high number of (teachers with) profiles with high Proximity, which is in line with previous work (e.g. den Brok et al. 2005; Ferguson and Fraser 1998; Speering and Rennie 1996).

While the findings of this study seem to indicate that additional styles might be necessary to describe the interpersonal climate in Australian primary education classes, future research is needed to verify these findings. No explanation could be provided, or was sought in this study, for the emergence of new teacher profiles. Also, teachers participated on a voluntary basis, which could have limited the range of interpersonal profiles found compared with what actually might be present in the population of primary science teachers in Australia. One indication for this was the fact that the selected classes had higher Enjoyment scores than classes excluded from the analyses because of missing data for perceptions of teacher-student interpersonal behaviour. In addition, no information was available with respect to the representativeness of our sample.

The outcomes of this study are important for both researchers and teachers. The results of this study show that there are several teaching styles that incorporate high amounts of both Influence and Proximity, properties which in the past have been associated with high scores for cognitive and affective student outcomes (Wubbels et al. 2006). Nevertheless, because distinctive differences exist between each of these styles, which range from Repressive to Supportive, teachers and educators should develop sensitivity and skill to distinguish between them. Such competencies might help in providing teachers with more detailed and adequate feedback and showing teachers that there are several ways to achieve their goals in the classroom.

For researchers and teachers alike, it is important to verify the stability of our findings and to provide more suggestions and explanations for differences between our findings and those in earlier work. Such research should also include qualitative data, such as interviews and observations of both teacher and student participants, in order to provide descriptions for newly-found types and to validate the labels attached to them. Moreover, such observations could also verify descriptions of existing types that have been found to apply to the Australian setting. While profiles might be similar in different cultures, it might very well be that they are based on different behaviours and situations, or inferred from different observational cues.

Open Access This article is distributed under the terms of the Creative Commons Attribution Noncommercial License which permits any noncommercial use, distribution, and reproduction in any medium, provided the original author(s) and source are credited. 


\section{Appendix}

Item wording and factor loadings for each item of the CLEQ used in the present study

\begin{tabular}{|c|c|c|c|c|}
\hline \multirow[t]{2}{*}{ Item } & \multirow[t]{2}{*}{ Item wording } & \multicolumn{3}{|c|}{ Factor loadings } \\
\hline & & $\mathrm{F} 1$ & $\mathrm{~F} 2$ & F3 \\
\hline Eq1 & $\begin{array}{l}\text { I like it when my work receives as much praise as } \\
\text { other students' work. }\end{array}$ & 0.642 & & 0.403 \\
\hline Eq2 & $\begin{array}{l}\text { I like to get the same amount of help from the teacher } \\
\text { as do other students. }\end{array}$ & 0.544 & & \\
\hline Eq3 & $\begin{array}{l}\text { I like to have the same amount of say in this class } \\
\text { as other students. }\end{array}$ & 0.851 & & \\
\hline $\mathrm{Eq} 4$ & I like to be treated the same as other students in this class. & 0.822 & & \\
\hline Eq5 & $\begin{array}{l}\text { I like it when I get the same chance to answer questions } \\
\text { as other students. }\end{array}$ & 0.746 & & \\
\hline Col1 & I like working in groups. & & 0.860 & \\
\hline Col2 & $\begin{array}{l}\text { I feel that it is important for the class to work together } \\
\text { as a team. }\end{array}$ & 0.422 & 0.498 & 0.524 \\
\hline $\mathrm{Col} 3$ & $\begin{array}{l}\text { I would rather decide what to do as a group than to make } \\
\text { a decision by myself. }\end{array}$ & & 0.669 & \\
\hline $\mathrm{Col} 4$ & It is important for me to be involved in class discussions. & 0.591 & & 0.440 \\
\hline Col5 & I like to work with other students. & & 0.762 & \\
\hline Con 1 & What I learn at home helps me to do things at school. & & & 0.787 \\
\hline Con2 & What I learn in school helps me to do things at home. & & & 0.743 \\
\hline Con 3 & $\begin{array}{l}\text { I feel that ideas I learn at school are similar to those } \\
\text { I learn at home. }\end{array}$ & & & 0.813 \\
\hline Con4 & What I learn in this class agrees with what I learn at home. & & & 0.776 \\
\hline Con5 & What I learn in this class helps me at home. & 0.494 & & 0.695 \\
\hline
\end{tabular}

Eq Equity, Col Collaboration, Con Congruence, F1 Factor loadings on factor analysis for factor 1, F2 Factor loadings of factor 2, F3 Factor loadings of factor 3. Only factor loadings larger than 0.4 are displayed

\section{References}

Ben-Chaim, D., \& Zoller, U. (2001). Self-perception versus students' perceptions of teachers' personal style in college science and mathematics courses. Research in Science Education, 31, 437-454.

Brekelmans, M. (1989). Interpersonal teacher behaviour in the classroom. [In Dutch]. Utrecht, The Netherlands: W.C.C.

Brekelmans, M., Levy, J., \& Rodriguez, R. (1993a). A typology of teacher communication style. In T. Wubbels \& J. Levy (Eds.), Do you know what you look like? (pp. 46-55). London: Falmer Press.

Brekelmans, M., Sleegers, P., \& Fraser, B. (2000). Teaching for active learning. In R. J. Simons, J. van der Linden, \& T. Duffy (Eds.), New learning (pp. 227-242). Dordrecht, The Netherlands: Kluwer.

Brekelmans, M., Wubbels, T., \& Levy, J. (1993b). Student performance, attitudes, instructional strategies and teacher-communication style. In T. Wubbels \& J. Levy (Eds.), Do you know what you look like? (pp. 56-63). London: Falmer Press.

Brekelmans, M., Wubbels, T., \& van Tartwijk, J. (2005). Teacher-student relationships across the teaching career. International Journal of Educational Research, 43, 55-71.

Copeland, W. D., Birmingham, C., de la Cruz, E., \& Lewin, B. (1993). The reflective practitioner in teaching: Toward a research agenda. Teaching and Teacher Education, 9(4), 347-359. 
den Brok, P. (2001). Teaching and student outcomes. Utrecht, The Netherlands: W. C. C.

den Brok, P., Fisher, D., Rickards, T., \& Bull, E. (2006). Californian secondary students' perceptions of their classroom learning environments. Educational Research and Evaluation, 12(1), 3-25.

den Brok, P., Fisher, D., \& Scott, R. (2005). The importance of teacher interpersonal behaviour for student attitudes in Brunei primary science classes. International Journal of Science Education, 27(3), $765-779$.

Dhindsa, H. S. (2005). Cultural learning environment of upper secondary students. International Journal of Science Education, 27(5), 575-592.

Dhindsa, H. S., \& Fraser, B. J. (2004). Culturally-sensitive factors in teacher trainees' learning environments. Learning Environments Research, 7, 165-181.

Fabrigar, L. R., Visser, P. S., \& Browne, M. W. (1997). Conceptual and methodological issues in testing the circumplex structure of data in personality and social psychology. Personality and Social Psychology Review, 1, 184-203.

Ferguson, P. D., \& Fraser, B. J. (1998). Changes in learning environment during the transition from primary to secondary school. Learning Environments Research, 1(3), 369-383.

Fisher, D., den Brok, P., \& Rickards, T. (2006). Factors influencing students' perceptions of their teachers' interpersonal behaviour: A multilevel analysis. In D. L. Fisher \& M. S. Khine (Eds.), Contemporary approaches to research on learning environments: World views (pp. 51-74). Singapore: World Scientific.

Fisher, D., Rickards, T., Goh, S., \& Wong, A. (1997). Perceptions of interpersonal teacher behavior in secondary science classrooms in Singapore and Australia. Journal of Applied Research in Education, 1(2), 2-11.

Fisher, D. L., \& Waldrip, B. G. (1999). Cultural factors of science classroom learning environments, teacher-student interactions and student outcomes. Journal of Science Education and Technology, $17(1), 83-96$.

Fisher, D. L., \& Waldrip, B. G. (2002). Measuring culturally sensitive factors of classroom learning environments with the CLEQ. In S. C. Goh \& M. S. Khine (Eds.), Studies in educational learning environments: An international perspective (pp. 27-48). Singapore: World Scientific.

Fraser, B. J. (1981). Test of science-related attitudes. Melbourne, Australia: Australian Council for Educational Research.

Fraser, B. J. (1998). Science learning environments: Assessment, effects and determinants. In B. J. Fraser \& K. Tobin (Eds.), International handbook of science education (pp. 527-564). Dordrecht, The Netherlands: Kluwer.

Fraser, B. J. (2002). Learning environments research: Yesterday, today and tomorrow. In S. C. Goh \& M. S. Khine (Eds.), Studies in educational learning environments: An international perspective (pp. 1-27). Singapore: World Scientific.

Fraser, B. J. (2007). Classroom learning environments. In S. K. Abell \& N. G. Lederman (Eds.), Handbook of research on science education (pp. 103-125). London: Routledge.

Fraser, B. J., \& Walberg, H. J. (2005). Classroom learning environments: Retrospect, context and prospect. International Journal of Educational Research, 43, 103-109.

Gaines, S. O., Panter, A. T., Lyde, M. D., Steers, W. N., Rusbult, C. E., Cox, C. L., et al. (1997). Evaluating the circumplexity of interpersonal traits and the manifestation of interpersonal traits in interpersonal trust. Journal of Personality and Social Psychology, 73, 610-623.

Leary, T. (1957). An interpersonal diagnosis of personality. New York: Ronald Press Company.

Levy, J., den Brok, P., Wubbels, T., \& Brekelmans, M. (2003). Students' perceptions of interpersonal aspects of the learning environment. Learning Environments Research, 6, 5-37.

Rickards, T., den Brok, P., \& Fisher, D. (2005). The Australian science teacher: A typology of teacherstudent interpersonal behaviour in Australian science classes. Learning Environments Research, 8, 267-287.

Speering, W., \& Rennie, L. (1996). Students' perceptions about science: The impact of transition from primary to secondary school. Research in Science Education, 26(3), 283-298.

Telli, S., Cakirgolu, J., \& den Brok, P. (2007a, August). The Turkish teacher: Profiles of teacher-student interpersonal behaviour in Turkish secondary science classes. Paper presented at the bi-annual meeting of the European Association for Research on Learning and Instruction, Budapest, Hungary.

Telli, S., den Brok, P., \& Cakiroglu, J. (2007b). Students' perceptions of science teachers' interpersonal behaviour in secondary schools: Development of the Turkish version of the Questionnaire on Teacher Interaction. Learning Environments Research, 10, 115-129.

Weber, S., \& Mitchell, C. (1996). Drawing ourselves into teaching: Studying the images that shape and distort teacher education. Teaching and Teacher Education, 12(3), 303-313. 
Wubbels, Th. (1992). Taking account of student teachers' preconceptions. Teaching and Teacher Education, $8(2), 137-149$.

Wubbels, Th., \& Brekelmans, M. (1998). The teacher factor in the social climate of the classroom. In B. J. Fraser \& K. G. Tobin (Eds.), International handbook of Science education (pp. 565-580). London: Kluwer.

Wubbels, T., \& Brekelmans, M. (2005). Two decades of research on teacher-student relationships in class. International Journal of Educational Research, 43, 6-24.

Wubbels, T., Brekelmans, M., den Brok, P., \& van Tartwijk, J. (2006). An interpersonal perspective on classroom management in secondary classrooms in the Netherlands. In C. Evertson \& C. S. Weinstein (Eds.), Handbook of classroom management: Research, practice and contemporary issues (pp. 1161-1191). New York: Lawrence Erlbaum Associates.

Wubbels, T., Brekelmans, M., \& Hermans, J. (1987). Teacher behavior: An important aspect of the learning environment. In B. J. Fraser (Ed.), The study of learning environments, Vol. 3 (pp. 10-25). Perth, Australia: Curtin University.

Wubbels, Th., Créton, H., \& Holvast, A. J. C. D. (1988). Undesirable classroom situations. Interchange, 19, $25-40$.

Wubbels, T., Créton, H. A, \& Hooymayers, H. P. (1985, April). Discipline problems of beginning teachers, interactional behavior mapped out. Paper presented at the annual meeting of the American Educational Research Association, Chicago.

Wubbels, T., \& Levy, J. (1993). Do you know what you look like? London: Falmer Press. 